\title{
Hazard connected to railway tunnel construction in karstic area: applied geomorphological and hydrogeological surveys
}

\author{
G. Casagrande, F. Cucchi, and L. Zini \\ Department of Geological, Environmental and Marine Sciences, University of Trieste, Italy \\ Received: 2 August 2004 - Revised: 4 October 2004 - Accepted: 5 October 2004 - Published: 23 February 2005 \\ Part of Special Issue "Natural and anthropogenic hazards in karst areas"
}

\begin{abstract}
In a mature karstic system, the realisation of galleries using the methodology of railway tunnel boring machine (TBM) involves particular problems due to the high risk of interference with groundwater (often subject to remarkable level variations) and with cavities and/or thick fill deposits. In order to define groundwater features it is necessary to investigate both hydrodynamic and karstification. To define and quantify the karst phenomenon in the epikarst of the Trieste Karst (Italy), an applied geomorphological approach has been experimented with surface and cavity surveys. The surface surveys have contributed to determining the potential karst versus the different outcropping lithologies and to define the structural setting of the rocky mass also through the realisation of geostructural stations and the survey of the main lines thanks to photo-interpretation. Moreover, all the dolines and the cavities present in the area interested by the gallery have been studied by analysing the probable extension of caves and/or of the secondary fill deposits and by evaluating the different genetic models. In an area $900 \mathrm{~m}$ large and $27 \mathrm{~km}$ long, which has been studied because of the underground karst, there are 41 dolines having diameters superior to $100 \mathrm{~m}$ and 93 dolines whose diameters range between 100 and $50 \mathrm{~m}$; the dolines whose diameters are inferior to $50 \mathrm{~m}$ are 282 . The entrances of known and registered cavities in the cadastre records are 520.
\end{abstract}

The hypogeal surveys have shown 5 typologies in which it has been possible to group all the cavities present in a hypothetical intersection with the excavation. The comparison between surface and hypogeal structural data and the direction of development of cavities has allowed for the definition of highly karstified discontinuity families, thus having a higher risk.

The comparison of the collected data has enabled to identify the lithologies and areas having major risk and thus to quantify the probability of intersection with the different cavity typologies for each area. To make an example, out of

Correspondence to: F. Cucchi

(cucchi@univ.trieste.it)
$27000 \mathrm{~m}$ of studied gallery 3930 are the metres expected to be at very high "karst risk". Out of these, as a whole 310 are risky because of the probable presence of gallery cavities, 2170 because of the probable presence of pits and sinkholes diffusely present under the dolines, and along $1450 \mathrm{~m}$ karst is particularly intense. Moreover, 2200 should be the metres in which the rocky mass will be particularly divided because of tectonic causes.

From a hydrogeological point of view a monitoring of water level has started to quantify water excursion, due to closeness of the railway tunnel to the mean water level. First results related to galleries intersection are here presented.

\section{Introduction}

The study for the construction of galleries in karst areas involve additional problems if compared to a standard railway tunnel-planning activity, both with respect to the scheduling of the preliminary geological surveys to be performed, and to the subsequent analyses to be carried out during the construction phase. In most cases, once the presence of karst phenomena has been ascertained, the problem of identifying voids is dealt with during the construction phase, through surveys conducted while the gallery excavation advances or - in cases of scarcely developed karst phenomena - through direct crossing of the void during the excavation phase. Studied cases of galleries crossing intensely karstified areas, and therefore requiring preliminary identification of voids due to the potential risks connected with the caves, such as to hamper the project feasibility, are not frequent (Beck and Pearson, 1995; Knez et al., 2004; Scesi and Papini, 1998).

In cases of intensely karstified areas, additional surveys are needed already while assessing the feasibility of the work proposed, in order to define the typology of the karst phenomena present in the area and to calculate their probability. So far, no study methodologies permitting to unquestionably identify the presence of a karst cave have been developed: geophysical surveys often lead to controversial results and 


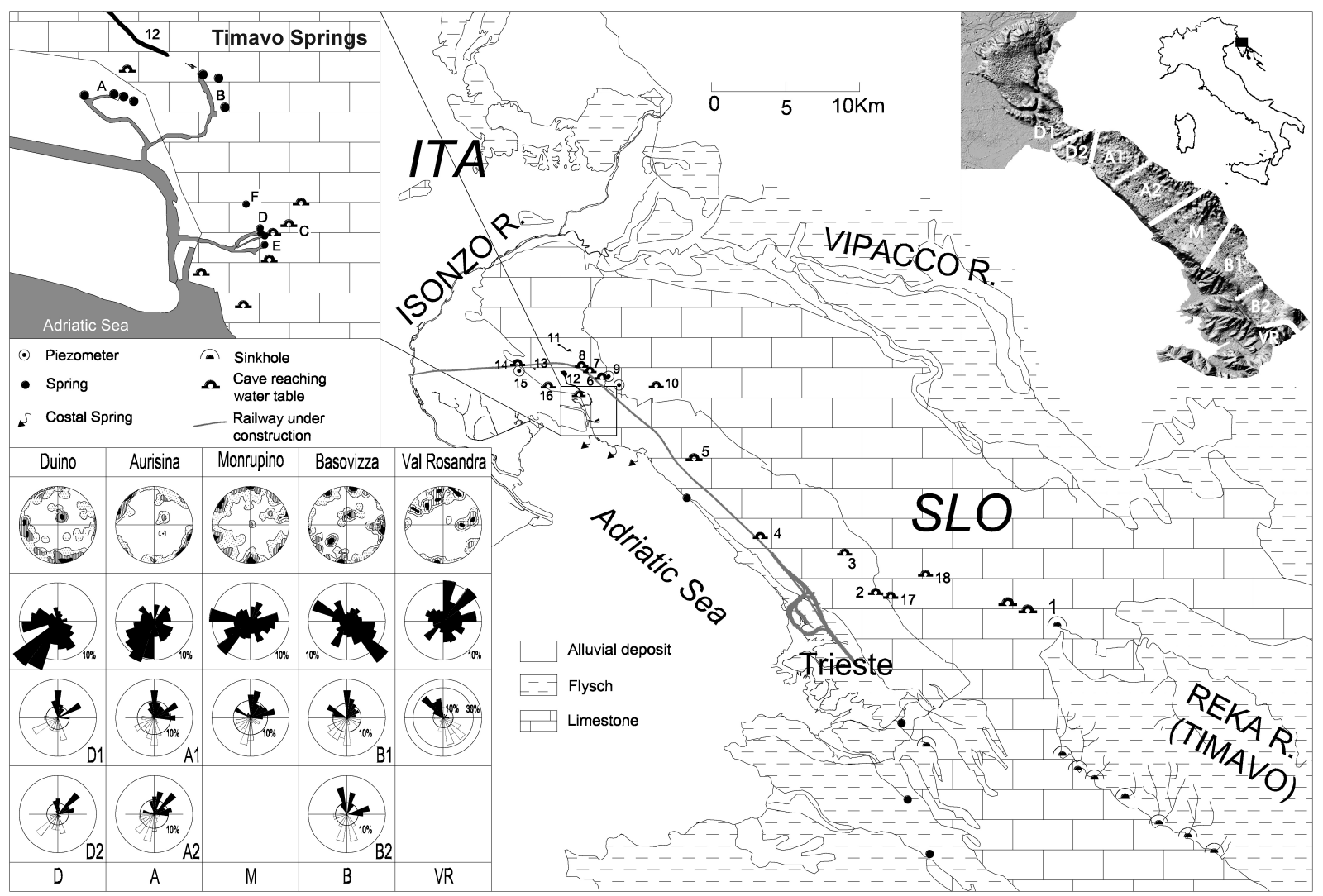

Fig. 1. General overview of the Classical Karst area and of the planned route for the Venice-Trieste high-speed railway tunnel (Ronchi dei Legionari-Trieste stretch). The railway tunnel crosses a thick succession of carbonate rocks (Higher Cretaceous-Eocene) and, near Trieste, affects non-karstifiable rocks (Flysch, Eocene). The structure of the limestone succession is a regular one as it is the western side of an anticline trending NW-SE. The stratification has a dip between $5^{\circ}$ and $30^{\circ}$ and trends towards SW. The railway tunnel rises up to $90 \mathrm{~m}$ above the sea level and can also be found at $300 \mathrm{~m}$ below the surface. For each of the structural sub-areas that have been identified (see top right box), the bottom left box shows: the poles of the discontinuity planes in the first line; the development direction of the caves in the second line, the main lineations identified via photo-interpreting in the third and the fourth line. Area of the Timavo Springs: A) Lisert Springs, B) Moschenizze Springs, C) Pozzo dei Colombi Cave, D) $1^{\text {st }}$ and $2^{\text {nd }}$ branch of the Timavo Springs, E) $3^{\text {rd }}$ branch of the Timavo Springs, F) Randaccio Springs. 1) Skocjanske Jame Cave, 2) Trebiciano Cave, 3) Lazzaro Jerko Cave, 4) Massimo Abyss, 5) Lindner Cave, 6) Comarie Cave, 7) Pozzo di Jamiano Cave, 8) Andrea Cave, 9) Brestovica Acqueduct, 10) Dolenca and Drca Cave, 11) Doberdò Lake, 12) Pietrarossa-Sablici Lake, 13) Mucille Lake, 14) Nevio Cave, 15) Piezometer, 16) Pozzo dei Protei di Monfalcone Cave, 17) Strsinkmi Doline Cave, 18) Kanjaduceva Cave.

interpretation, thus calling for assessments via geognostic surveys, which only have limited local validity in karst areas. The application of a high number of analyses can often be sustainable only in cases of small gallery stretches or of detailed studies in areas whose risks have already been ascertained. The case under examination is a preliminary feasibility study for a $27 \mathrm{~km}$ long railway tunnel in one of the most karstified areas in Europe (Fig. 1), with planned route altitudes interfering both with the epikarst and with the vadose zone and the aquifer oscillation zone. Given the extension of the surveyed area and the study typology - which is aimed at a preliminary definition and quantification of the potential karst-related problems - the methodology adopted consists in applied geological and hydrogeological surveys, to be confronted - where possible - with the data resulting from direct and indirect geological surveys.

\section{The problem of highly developed karst}

The presence of karst phenomena and of a high density of voids has already been established: there are 2900 caves in an area stretching over $230 \mathrm{~km}^{2}$; their average density is 12 cave $/ \mathrm{km}^{2}$, with peaks of 70 caves $/ \mathrm{km}^{2}$. Of these caves, 126 cover over $100 \mathrm{~m}$, and 70 are deeper than $100 \mathrm{~m}$. 5,300 dolines are present in the area, 440 of which have a diameter higher than $100 \mathrm{~m}$ and 1300 higher than $50 \mathrm{~m}$. Highly valuable is the age of the most developed morphologies, and the first occurrence of karst phenomena probably dates back to earlier than pre-Messinian Ages. Karst evolution is still active today. The morphological traits to be found in the wider caves indicate alternate enlargement, filling and emptying phases, with many renewal phases. Vertical shafts are the most frequent landforms near the surface but are actually 


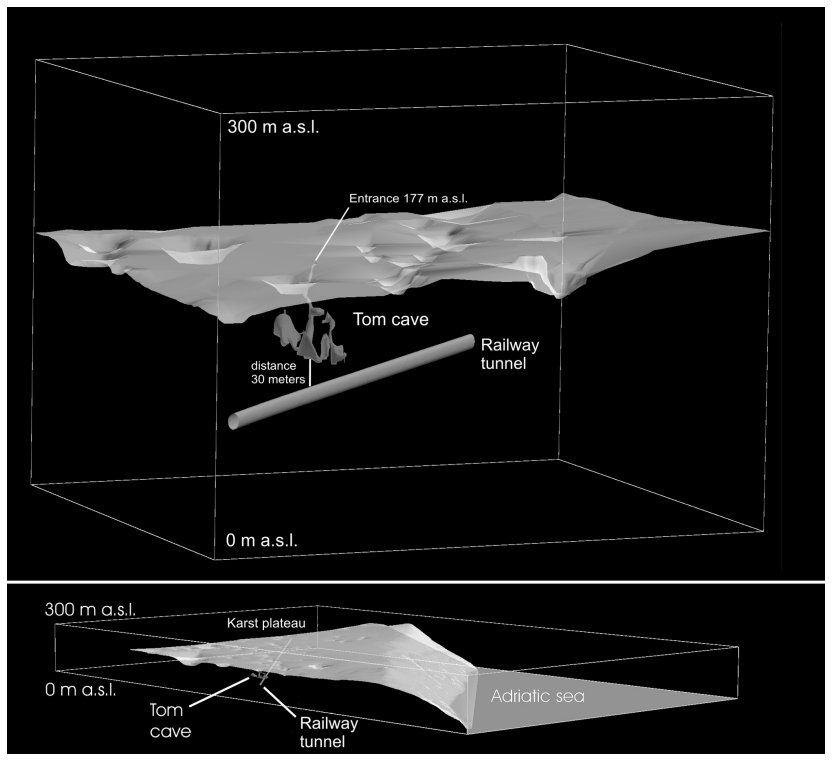

Fig. 2. 3D model of the TOM Cave area processed with GOCAD. In this area, the railway tunnel is located $100 \mathrm{~m}$ below the surface. The TOM Cave has been explored up to $67 \mathrm{~m}$ below the surface but it would be reasonable to suppose the presence of voids obstructed by collapse deposits reaching the height of the railway tunnel.

present at all heights. The whole territory is characterized by the intersection of morphologies linked to different genetic phases, with a consequent remarkable variety of typologies and void dimensions, which further complicates studies on this field.

From a geotechnical standpoint, the quality of the rock crossed by the gallery is excellent and the areas and volumes presenting problems of intensely fractured rock mass are rare. These features are in contrast with the high karstification level, which also presents particularly mature karst landforms. This considered, it ought to be clear that identifying the voids that can potentially be involved in the excavation area is not sufficient to assess the real hazard connected to the railway tunnel construction. Crossing ancient karst voids currently filled by secondary deposits can, in fact, prove more risky than crossing a simple void. Secondary filling deposits can variably range from rock blocks (centimetric to metric in size), flowstone and sandy-clayey to siltclayey sediments. This material is of a poor quality from a geotechnical standpoint and often presents an unstable structure that cannot normally be consolidated during the excavation phase. The assessment of the extension of the abovementioned filling deposits can only be hypothesized on the basis of specific geomorphological cavity surveys.

\section{Methods, surveys and results}

This said, it ought to be clear that the hazard arising from the mature-karst factor can vary depending on the problems considered: crossing and surpassing of caves, the protection of caves, interference between aquifer and railway tun-

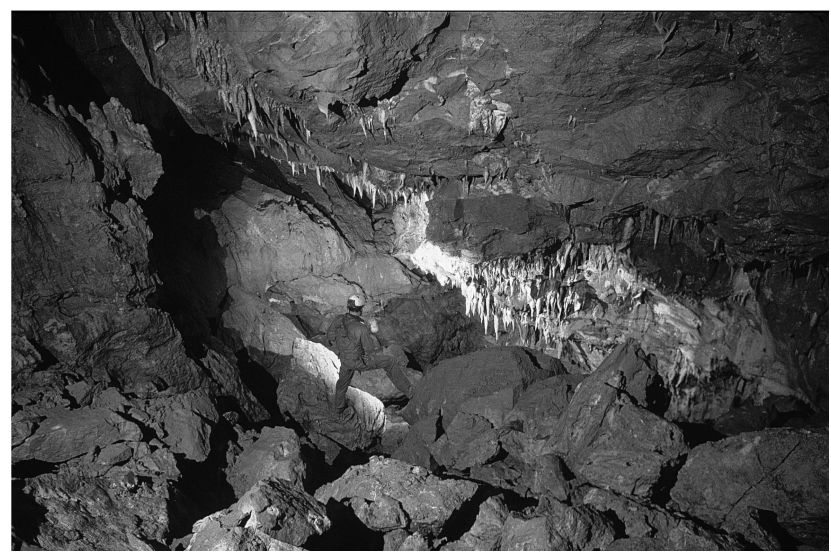

Fig. 3. Breakdown at the bottom of the TOM Cave.

nel, aquifer contamination. Applied geomorphological and hydrogeological surveys are the starting point to tackle the above-mentioned issues and to plan detailed surveys.

\subsection{Crossing and surpassing of caves}

The Classical Karst is a vastly explored territory from a speleological standpoint. Clearly, the known voids only account for a small part of the voids that are actually present within the rock mass. Nonetheless, the cavities present in the studied area, with their density and morphology, form a sample that - especially if considered in the light of the geological features present (lithology and rock fragmentation) - permits to classify areas characterized by different karst level and typology (Fig. 1). The problem of identifying a single unknown void can only be solved via direct surveys. A statistical study of the development direction of cavities as well as of the discontinuity direction, for example, consents to hypothesize the probability of intersection between the railway tunnel and the cavities close to the railway tunnel route, not accessible to the speleologist due to the presence of secondary filling deposits.

The most useful results to this aim have emerged from a comparison between the statistical data on the cavity direction and those relating to the landforms connected to the same directions: simple shafts appear to be structured on fractures trending $\mathrm{N}-\mathrm{S}$, while the wide syngenetic galleries are guided by the dip of strata and are therefore perpendicular to the planned railway tunnel. In the hypothesis of an intersection with these wide voids, whose diameter can range between a few metres and $40-50 \mathrm{~m}$ and whose length can reach up to hundreds of metres, the railway tunnel route has been planned so as to reduce the risk caused by the wide volumes involved to the minimum, as it would run perpendicularly to the most probable development direction of the karst galleries. The vertical voids structured along fractures trending N-S are the least hazardous cases because they have limited dimension (maximum diameter 20-30 m) - statistically speaking - and are only rarely associated to other adjoining voids. 

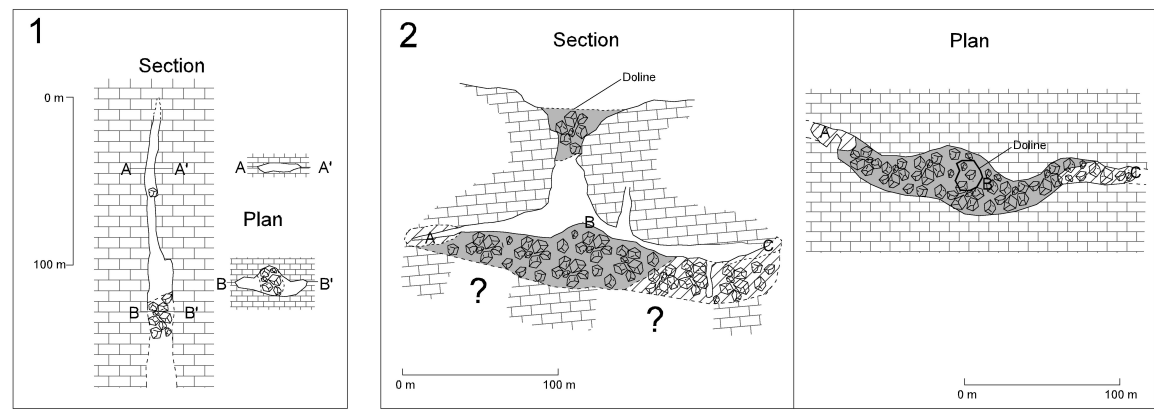

mud, clay
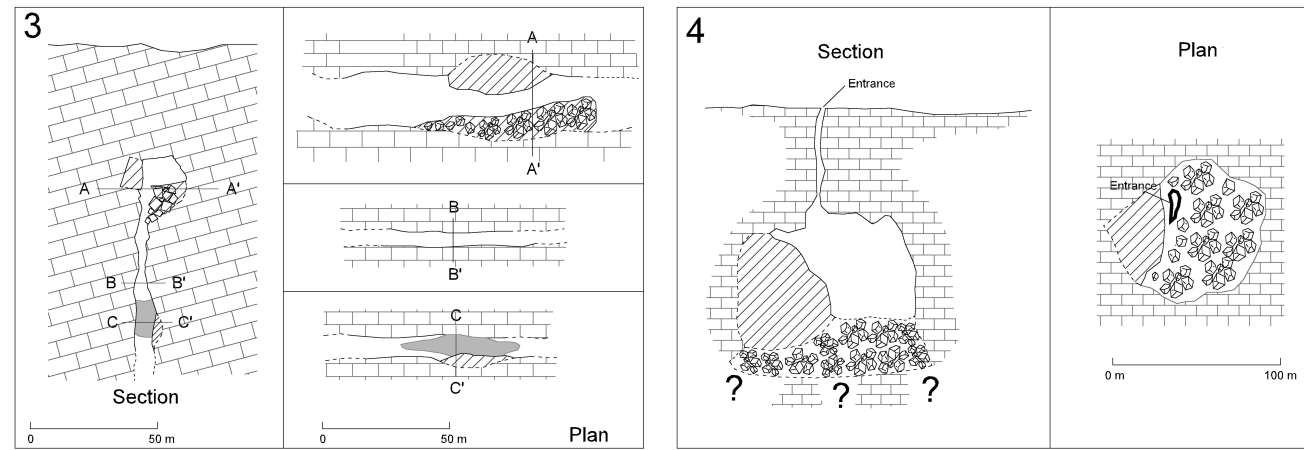

Fig. 4. Scheme of the cavity typologies and of the relative size of the voids potentially crossable by the railway tunnel. Typology 1 (pits) is the most frequent but least hazardous case. Typologies 2 and 3 (galleries) are average frequent cases, and their hazard rate varies according to the thickness and type of fillings present and to the void orientation compared to the railway tunnel direction and height. Typology 4 (big chambers) is the rarest case, and could affect the work feasibility.

As far as the known cavities are concerned, we have examined 60 cavities whose entrance opens on the planned route or that, due to their underground development, lie within a $100 \mathrm{~m}$ area from the planned route. Particular attention has been paid to the expansion likelihood of the initial void in cases of cavities partially filled by secondary deposits, whose actual development could progressively affect the railway tunnel area.

A clear example is provided by the TOM cave (3949/2442VG, Fig. 2), which opens at an altitude of $177 \mathrm{~m}$ above the sea level and at a plan distance of $40 \mathrm{~m}$ from the planned railway tunnel route. The cave is formed by a series of small shafts opening into a $35 \times 50 \times 30 \mathrm{~m}$ wide cave. This is a void originated by the coalescence of two galleries, later evolved into a collapse cave. The planned track is located at $30 \mathrm{~m}$ below the cave (Fig. 2). Geological cavity surveys showed the presence of thick secondary collapse deposits and calcite concretions on the bottom, with evidence of still ongoing emptying and collapse phenomena (Fig. 3). Though the intersection case is only supposed, the conditions for the advancement of the railway tunnel are surely diffusedly unstable; therefore particular caution is to be paid for a $100 \mathrm{~m}$ stretch. In similar cases, the assessment of the extension of the filling deposits can only be hypothesized on the basis of detailed geomorphological surveys conducted inside the cave, in order to detect the geometry of the initial void in the rock, where possible.
In order to meet the future planning requirements for surpassing voids, the morphology of all 3200 caves present in the Trieste Karst has been analysed from a geological point of view. The caves have then been grouped into simplified morphological typologies according to the common problems they could present during crossing (Fig. 4). For any cave typology, the maximum and minimum void size and the hazard level in case of crossing have been indicated. In the crossed area, for example, $60 \%$ of the known cavities are represented by simple shafts - that is, vertical voids with diameter ranging between a few metres and $20-30 \mathrm{~m}$ and depth ranging between a few metres and some hundred metres. Risk in case of crossing is low, because the landforms are primary ones, with scarce filling deposits: clearly, risk in case of void crossing still exists.

The other general cave typologies that have been recognized according to statistical parameters are the following:

- Galleries and caves connected to collapse dolines (Fig. 4, case 2), with entrances whose diameter can reach up to some hundred metres and whose maximum depth amounts to about a hundred metres. These can be either completely or only partially filled with collapse deposits; in this case, they provide access to lateral galleries whose diameter often exceeds $20 \mathrm{~m}$. These are rare landforms (10\%), which nonetheless pose marked crossing problems. 


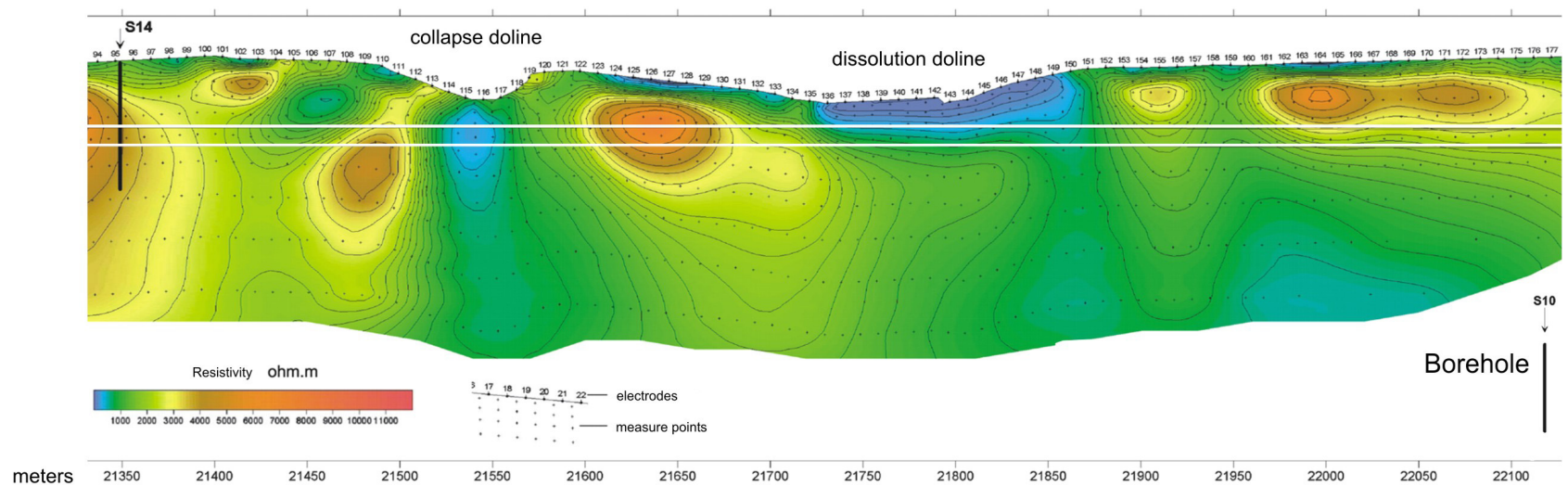

Fig. 5. Collapse and dissolution dolines highlighted by the geoelectric survey conducted on the surface along the railway tunnel (courtesy of ITALFERR S.p.A. and Geoinvest S.r.l.). The total length of the electric stretch is $2000 \mathrm{~m}$, equidistance between electrodes is $10 \mathrm{~m}$, the configuration is the Schlumberger's one.

- Syngenetic galleries (Fig. 4, case 3) that may or may not be canyon-like. The canyon usually is only limited to few metres in width and about $10 \mathrm{~m}$ in depth. These are average frequent landforms (30\%) and the intersection risk increases depending on the void dimensions, on the presence or absence of filling material and on the direction of the cave-tunnel intersection.

- Big chambers (Fig. 4, case 4), rare case that could hamper the project feasibility. In the Trieste Karst, the wider chamber is the Gigante cave, which also is the widest tourist cave in the world. It consists of a $120 \times 90 \mathrm{~m}$ large chamber, $110 \mathrm{~m}$ high, with voluminous and thick collapse deposits on its floor. The presence of these landforms is not signalled by particular geological or geomorphologic features on the surface.

On the whole, the applied geomorphological studies of the cavities present in a $900 \mathrm{~m}$ long asymmetrical area, parallel to the planned route, combined with surface geological (lithology) and structural (photo-interpreting, structural stations) surveys, have made it possible to subdivide the railway tunnel length into smaller tracts according to their higher or lower risk degree of cavity intersection. Out of $27000 \mathrm{~m}$, $3930 \mathrm{~m}$ have been considered at high "karst risk", out of which $310 \mathrm{~m}$ are likely to present voids at the railway tunnel level, $2170 \mathrm{~m}$ vertical shafts, and $1450 \mathrm{~m}$ are exposed to intense karst phenomena, due to the presence of numerous voids close to each other, whose extension might exceed the known one.

The problem of a correct identification of single unexplored voids can only be solved via the excavation of a pilot railway tunnel; in this case, the definition of the probable extension and typology of the karst phenomena on the basis of the characteristics of the cavities that are already known makes it possible to estimate the problems that could arise from the crossing of voids and to preliminarily assess the stretches exposed to karst risk.

\subsection{Caves preservation}

The planned railway tunnel intersects 3 already known cavities. Currently, Italy does not have a specific legislation aiming at safeguarding karst cavities. The national law (1497/1939) for the protection of natural beauties refers to "noteworthy natural beauty or geological peculiarity" but a national updated list of protected cavities does not exist, as does not a unified procedure for the safeguarding of a cavity, nor does the current legislation establish the key requirements a cavity has to meet to be safeguarded. In the Friuli Venezia Giulia region, the D.G.R. (Regional Council Deliberation) 4046/1996 established environmental constraints for 25 karst cavities of remarkable beauty and interest. None of the cavities crossed by the railway tunnel is included in this list, which means that they could potentially be destroyed unless some ad hoc procedures are temporarily put in force to effectively acknowledge some natural interest peculiarities pertaining to the interested cavities. A major problem could arise if new cavities with entrance opening onto the railway tunnel were found. In this case, as happened during the construction of other works, the commissioning body is expected to require a topographical survey of the cavities and, if they prove to be of some interest, the creation of a permanent access system.

\subsection{Collapse and dissolution dolines}

As far as the feasible surface surveys are concerned, it is important to distinguish between collapse and dissolution dolines (Ford and Williams, 1989; White, 1988), because they are indicative of different underlying karst phenomena. Collapse dolines are often associated to extensive vertical collapses, and therefore to the presence of large voids and thick filling deposits, whereas dissolution dolines are usually associated to the presence of smaller vertical cavities-sinkholes. In the examined area, a sharp distinction between the two above-mentioned landforms may be problematic because of the presence of mature karst phenomena, whose evolution 

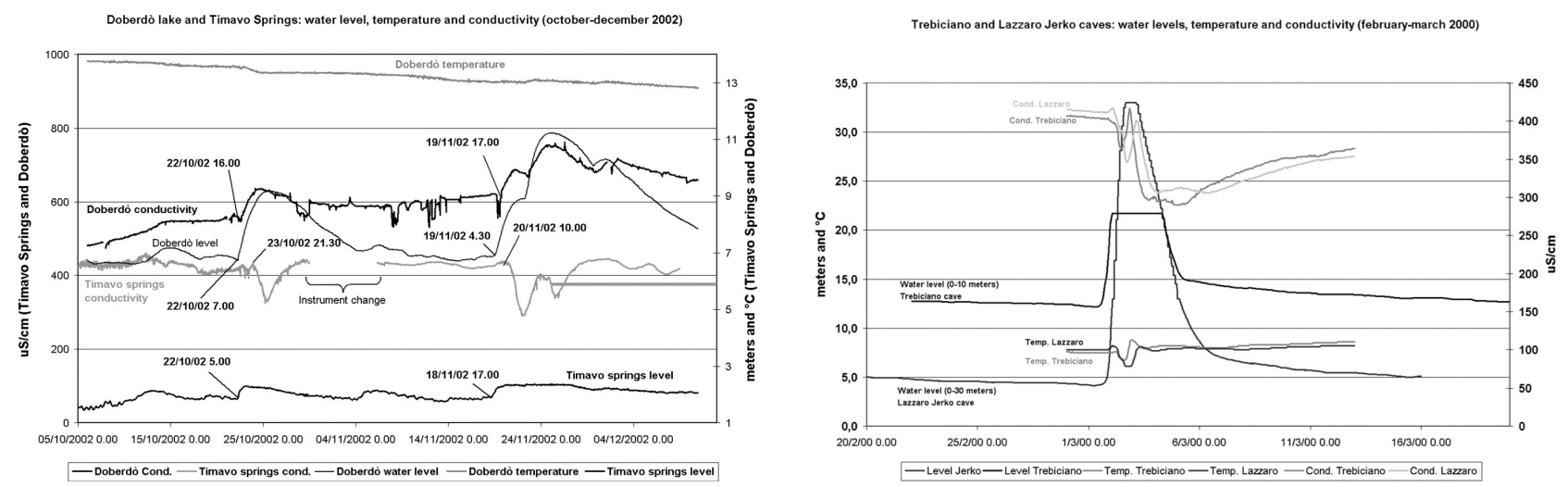

Fig. 6. Changes in level, temperature and conductivity in the northern and southern sectors. Left: Doberdò Lake and Timavo Springs; right: Trebiciano Cave and Lazzaro Jerko Cave (for the location see Fig. 1).

has been going on for millions of years. The initial surface landforms are difficult to recognize and the currently existing dolines can be the result of an evolution process induced by pre-existing morphologies that have then been eroded, as in the case of roofless caves (Andrian et al., 2001; Sauro, 2003). In order to emphasize the technical utility of the above-stated distinction, Fig. 5 shows the result of an electric survey carried out along sample stretches of the planned railway tunnel. In the collapse dolines, the low-resistivity anomaly clearly propagates vertically and deeply, and is probably linked to the presence of collapse deposits (more or less cemented debris) mixed with clayey-silt sediments. As far as the dissolution dolines are concerned, a deep extension of the deposit is limited, thus forming the typical pot-like form and leading the bottom to be filled by prevalently clay and silt deposits. Whereas in the first case the crossing of the doline will have to be performed with accurate consolidation techniques, in the latter the railway tunnel is at risk only when the crossing altitudes are too close to those at the bottom of the doline.

\subsection{Hydrogeological risk}

The area crossed by the railway tunnel is one of the most valuable karst aquifers in Italy. It comprises two catchment areas for drinking water located near the railway tunnel, one in the Slovenian (Brestovica, Fig. 1) and one in the Italian territory (Timavo Springs area, Fig. 1). The Timavo springs and their feeding area, stretching to the course of the Higher Timavo in Slovenia ( $40 \mathrm{~km}$ to the South-West), are one of the highest-discharge regions in Italy (medium discharge $30 \mathrm{mc} / \mathrm{s}$ ). The potential risks connected with the railway tunnel construction both concern the feasibility and the sustainability of the planned work, depending on whether the focus lies on the risk of railway tunnel enlargement or on the need to safeguard the aquifer and keep the spring discharge.

From a karst hydrological standpoint, given the scarcity and the limited local value of the observation points on the aquifer, identification of the discharge direction and definition of underground feeding basins are only possible via tracers - both natural and artificial - and simple hydrogeological balances (input from river catchment and rain, output from springs).

In mature karst aquifers, as in the studied case, the watertable heights can sensibly vary, even when located at close distance: sectors close to the springs and located below the average phreatic level might be dry as, vice versa, sectors that are distant from the springs and decidedly above the average phreatic level might be occasionally interested by remarkable water flows. In such cases, defining the modality of underground drainage, the type of drains, the ratio between fissures and karst conduits, is only possible by applying continuous monitoring to waters characterized by different chemicalphysical parameters (usually level, temperature, conductivity).

In the specific case of the Classical Karst, several studies and tests with tracers have already defined the main underground water flow directions and the relation between springs and recharge areas (Galli, 1999). Two main independent feeding and discharging areas exist, one of which trends SE-NW and the other N-S, both converging toward the Timavo spring area (Cucchi and Zini, 2002; Fig. 1).

In the South-westernmost area, the simultaneous monitoring of 4 cavities located on the water-discharge axis (Skocjanske Jame, Trebiciano Abyss, Grotta Meravigliosa di Lazzaro Jerko Cave, Lindner Cave) showed that the water drainage does not occur but along few and important drains, with actual speed of some $\mathrm{m} / \mathrm{h}$. In some stretches, the aquifer height can fluctuate by some dozens metres. In the area between the Trebiciano Abyss and the Lazzaro Jerko Cave, in particular, rises during the flood are simultaneous, and the temperature and conductivity curves show an almost identical trend, with a shift ranging between 8 and $20 \mathrm{~h}$, which demonstrates a deep and under-pressure circulation (Cucchi et al., 2000; Fig. 6). The highest fluctuations (up to $110 \mathrm{~m}$ above the sea level in the Trebiciano Abyss) depend on the failure to discharge the flood wave by the drain system located downstream, and induce high though only local hydraulic gradients. Fluctuations up to $20-30 \mathrm{~m}$ are supposed to be linked to the regular propagation of the hydraulic gradi- 
ent and should therefore extend laterally. Given the absence of natural observation points and considering the entity of the foreseeable discharges, some boreholes equipped with piezometers have already been excavated to monitor eventually present aquifer waters.

Monitoring of the western area, where the railway tunnel heights are close to the aquifer level, has been possible thanks to several natural observation points and to some adhoc positioned piezometers. Preliminary monitoring highlighted that the water circulation in this area features longlasting but limited fluctuations, with homogeneous factors due to the presence of both karst and fissured network with more frequent and limited drains (Fig. 6). On the hydrograph of the flood curves, the contribution of infiltration meteoric waters is not visible because it is hidden by the mixing with supply waters or waters coming from a long distance. In this particular case, geochemical monitoring permitted to distinguish water contributions to the aquifer coming from the outside of the karst infiltration basin, induced by subriver seepage of the Isonzo river, which flows in an alluvial plain bordering the limestone landforms located to the North (Doctor et al., 2000; Flora et al., 1990). The homogeneity of the data pertaining the water level in this area permits to extrapolate a maximum and a minimum level water table. In the region close to the water catchment areas of Brestovica's water supply system (Slovenia), however, feeding contributions and local discharge directions - important parameters for the aquifer protection - have not been defined yet. 7 piezometers have therefore been installed to perform continuous chemical-physical monitoring of the waters and to complement the data that can be taken from the 4 natural observation points.

Although there are only two hazardous stretches, concentrated in the spring area, with respect to the vulnerability of the karst aquifer, in a territory as the Classical Karst - given the structure of the karst network, the typology and the discharge speed of underground waters - the only viable solution to effectively protect the aquifer is the complete isolation between railway tunnel and karst aquifer. The survey to be adopted to assess any possible diffusion of pollutants from the railway tunnel to the springs will have to be selected on the basis of monitoring sessions and tests with tracers, also bearing in mind that any form of pollution would only take a few days to reach the aquifer and the springs in such a mature karst environment, and that the aquifer has practically no self-purification capacity.

\section{Conclusions}

This paper illustrates the methodology adopted to define the geological risks that can occur along the route of a $27 \mathrm{~km}$ long gallery, engraved in highly karstified rocks. Assessing the entity and the typology of the hypogeal karstification of such a long stretch is not as simple as it may seem, as it is not easy to define the fluctuations of the aquifer in a mature karst environment.
The entity of underground karstification was hypothesized basing on specific geological surface and speleological surveys in the caves located in proximity of the planned track. The doline density and typology (dissolution or collapse dolines) have been considered as surface indexes of deep karstification, alongside the presence of master joints and of intensely tectonised areas, the stratification frequency (bed thickness), the lithological characteristics (more or less soluble limestone).

In the caves located along the track, geological and geomorphological influence on the development of hypogeal pits, galleries and chambers has been analysed. This influence has been in turn compared with that guiding epigeal and hypogeal karstification throughout the entire Classical Karst region. Thus, the different typologies of cave present have been statistically ascertained, as have their frequency and their level of risk with respect to the railway tunnel construction - risk that was found to be dramatically variable depending on the potential fill deposits of the caves.

The most dangerous areas from the standpoint of the construction of two parallel railway tunnels have been delimited, by hypothesizing that - out of $27000 \mathrm{~m}$ - only 310 are hazardous due to the probable presence of gallery cavities (diameter of the void to cross ranging between 5 to some tens of metres), and present additional hazard due to the presence of fill deposits. $2170 \mathrm{~m}$ are at risk because of the probable presence of pits (few problems for the crossing of the void, usually limited in size, and with scarce fill deposits) and because of sinkholes diffusedly present under the dolines. 2200 should be the metres in which the rocky mass will be particularly divided because of tectonic causes. The known karst phenomena and the caves registered in the cadastre records already allow for the definition of other numerous stretches - totalling $1450 \mathrm{~m}$ - where underground karst phenomena ought anyway to be taken into account, and are likely to be particularly present and widespread.

Since the rich hypogeal aquifer is used to provide water to the water-supply system, monitoring of the system hydrodynamics, performed by considering as many as 21 water points (caves with base water level and boreholes), 5 springs, 3 karst lakes, has led to the definition of the average aquifer depth and its excursions. Two areas have thus been identified, one of which located in the spring zone, where the groundwater is approximately at the sea level, and concerning the first 5 out the total $27 \mathrm{~km}$ of the track. The second area is characterized by a groundwater level positioned at a depth that is anyway lower than $13 \mathrm{~m}$ above sea level, with decidedly more marked excursions, and peak values exceeding $100 \mathrm{~m}$.

In a territory that is subject to highly developed karst phenomena, as is the Classical Karst, specific geological, geomorphological and hydrogeological surveys are indispensable to define deep karstification, and should be extended to viable caves. This is particularly true where the works planned are located at a certain depth from the surface, and the underground cannot therefore be investigated via standard geophysical procedures. 
Edited by: M. Parise

Reviewed by: G. Kaufmann, W. White and another referee

\section{References}

Andriani, F., Cucchi, F., Marinetti, E., and Zini, L.: Doline di crollo e doline di dissoluzione nel Carso triestino, Studi Trentini di Scienze Naturali, Acta Geologica, 77, 117-126, 2001.

Beck, B. F. and Pearson, F. M.(eds.): Karst geohazards - Engineering and environmental problems in karst terrain, Proceedings of the Fifth Multidisciplinary Conference on Sinkholes and the Environmental Impacts of Karst, A. A. Balkema, 581, 1995.

Cucchi, F., Casagrande, G., Manca, P., and Zini, L.: Il Timavo ipogeo tra l'Abisso di Trebiciano e la Grotta Meravigliosa di Lazzaro Jerko (Carso Classico Triestino, Italia), Le Grotte d'Italia, V, 2, 39-48, 2001.

Cucchi, F., and Zini, L.: Underground Timavo river monitoring (Classical Karst), Acta Carsologica, Ljubljana, 31, 1, 75-84, 2002.
Doctor, D. H., Lojen, S., and Horvat, M.: A stable isotope investigation of the Classical Karst aquifer - evaluating karst groundwater components for water quality preservation, Acta Carsologica, 29, 1, 79-92, 2000.

Flora, O., Galli, G., Negrini, L., and Longinelli, A.: Studio geochimico-isotopico di alcune sorgenti carsiche - un nuovo modello idrologico, Atti Mem. Comm. Grotte “E. Boegan”, 29, 83-102, 1990.

Ford, D. and Williams, P.: Karst geomorphology and hydrology, Unwin Hyman Ltd Ed., London, 601, 1989.

Galli, M.: Timavo - Esplorazioni e studi, Suppl. n. 23 di Atti Mem. Comm. Grotte “E. Boegan”, Trieste, 195, 1999.

Knez, M., Slabe, T., and Sebela, S.: Karstification of the aquifer discovered during the construction of the expressway between Klanec and Crni kal, Classical Karst, Acta Carsologica, 33/1, 205-217, 2004.

Sauro, U.: Dolines and sinkhole - aspect of evolution and problems of classification, Acta Carsologica, 32/2, 41-52, 2003.

Scesi, L., and Papini, M.: Studi geologici nei progetti di gallerie, Geo-gaph S.n.c. Ed., Segrate., 244, 1998.

White, W. B.: Geomorphology and hydrology of karst terrains, Oxford University Press, Oxford, UK, 464, 1988. 